\title{
Deficiency of dolichol-phosphate-mannose synthase-1 causes congenital disorder of glycosylation type Ie
}

\author{
Timo Imbach, ${ }_{1}^{1}$ Barbara Schenk, ${ }^{2}$ Els Schollen, ${ }^{3}$ Patricie Burda, ${ }^{2}$ Andreas Stutz, ${ }^{1}$ \\ Stephanie Grünewald, ${ }^{3}$ Nicola M. Bailie, ${ }^{4}$ Mary D. King, ${ }^{4}$ Jaak Jaeken, ${ }^{5}$ Gert Matthijs,${ }^{3}$ \\ Eric G. Berger, ${ }^{1}$ Markus Aebi, ${ }^{2}$ and Thierry Hennet ${ }^{1}$ \\ ${ }^{1}$ Institute of Physiology, University of Zürich, 8057 Zürich, Switzerland \\ ${ }^{2}$ Institute of Microbiology, Swiss Federal Institute of Technology, 8092 Zürich, Switzerland \\ ${ }^{3}$ Center for Human Genetics, Catholic University Leuven, 3000 Leuven, Belgium \\ ${ }^{4}$ Neurology Department, The Children's Hospital, Dublin 1, Ireland \\ ${ }^{5}$ Department of Pediatrics, University Hospital Leuven, 3000 Leuven, Belgium \\ Address correspondence to: Thierry Hennet, Institute of Physiology, Winterthurerstrasse 190, CH-8057 Zürich, Switzerland. \\ Phone: 41-1-635-5080; Fax: 41-1-635-6814; E-mail: thennet@access.unizh.ch. \\ Patricie Burda's present address is: Howard Hughes Medical Institute, Division of Cellular and Molecular Medicine, University of \\ California-San Diego, 9500 Gilman Drive, La Jolla, California 92093, USA. \\ Timo Imbach and Barbara Schenk contributed equally to this work.
}

Received for publication October 15, 1999, and accepted in revised form December 7, 1999.

Congenital disorders of glycosylation (CDG), formerly known as carbohydrate-deficient glycoprotein syndromes, lead to diseases with variable clinical pictures. We report the delineation of a novel type of CDG identified in 2 children presenting with severe developmental delay, seizures, and dysmorphic features. We detected hypoglycosylation on serum transferrin and cerebrospinal fluid $\beta$ trace protein. Lipid-linked oligosaccharides in the endoplasmic reticulum of patient fibroblasts showed an accumulation of the dolichyl pyrophosphate $\mathrm{Man}_{5} \mathrm{GlcNAc}_{2}$ structure, compatible with the reduced dolichol-phosphate-mannose synthase (DolP-Man synthase) activity detected in these patients. Accordingly, 2 mutant alleles of the DolP-Man synthase DPM1 gene, 1 with a 274C>G transversion, the other with a $628 \mathrm{delC}$ deletion, were detected in both siblings. Complementation analysis using DPM1-null murine Thy1-deficient cells confirmed the detrimental effect of both mutations on the enzymatic activity. Furthermore, mannose supplementation failed to improve the glycosylation status of DPM1-deficient fibroblast cells, thus precluding a possible therapeutic application of mannose in the patients. Because DPM1 deficiency, like other subtypes of CDG-I, impairs the assembly of N-glycans, this novel glycosylation defect was named CDG-Ie.

J. Clin. Invest. 105:233-239 (2000).

\section{Introduction}

The detection of hypoglycosylation of proteins based on rapid assays such as isoelectric focusing of serum transferrin has led to the identification of several novel defects of $\mathrm{N}$-linked glycosylation. The related diseases have been classified as congenital disorders of glycosylation (CDG), formerly known as carbohydrate-deficient glycoprotein syndromes $(1,2)$. In keeping with the importance of oligosaccharides for glycoprotein functions (3), defective glycosylation leads to various clinical presentations, such as dysmorphism, encephalopathy, coagulation disorders, and other organ dysfunctions.

To date, 5 types of CDG have been characterized at the biochemical and genetic level. The currently established subtypes of CDG-I are caused by deficiencies in various compounds. CDG-Ia is caused by a defect in the PMM2 gene and a resulting deficiency in phosphomannomutase (4). The PMI gene is responsible for CDG-Ib and its characteristic deficiency in phosphomannose isomerase $(5,6)$. CDG-Ic is linked to the ALG6 gene and a deficiency in $\mathrm{Man}_{9} \mathrm{GlcNAc}_{2}-\mathrm{PP}$ -
Dol-dependent $\alpha 1,3$-glucosyltransferase $(P P$-Dol $=$ dolichyl pyrophosphate) (7-9), and CDG-Id is caused by a defect in $A L G 3$ and a resulting deficiency in $\mathrm{Man}_{5} \mathrm{GlCNAc}_{2}$-PP-Dol-dependent $\quad \alpha 1,3$-mannosyltransferase (10). All of these defects lead to incomplete biosynthesis of lipid-linked $\mathrm{Glc}_{3} \mathrm{Man}_{9} \mathrm{GlCNAc}_{2}$ in the endoplasmic reticulum (ER) and subsequent hypoglycosylation of nascent proteins. By contrast, deficiency of the Golgi-localized $N$-acetylglucosaminyltransferaseII enzyme in CDG-IIa leads to defective maturation of complex-type N-linked glycans (11).

The assembly of lipid-linked oligosaccharides takes place at the membrane of the ER. First, $\mathrm{Man}_{5} \mathrm{GlcNAc}_{2}-$ $P P$-Dol is assembled at the cytoplasmic side of the membrane; UDP-GlcNAc and GDP-Man serve as sugar donors. After the flipping of the oligomannose core into the luminal side of the ER, 4 mannose residues and 3 glucose residues are added using dolichol-phosphatemannose (DolP-Man) and dolichol-phosphate-glucose (DolP-Glc), respectively, as donor substrates (Figure 1) (12). DolP-Man is synthesized from GDP-Man and DolP by DolP-Man synthase. The human enzyme con- 
Table 1

Clinical data of the 2 CDG-le patients

\begin{tabular}{|c|c|c|}
\hline & Sib1 (boy) & Sib2 (girl) \\
\hline Pregnancy & Normal & Normal \\
\hline Delivery & Normal, at term & Normal, at term with mild shoulder dystocia \\
\hline Apgar score & 6 at $1 \mathrm{~min}, 9$ at $5 \mathrm{~min}$ & 7 at $1 \mathrm{~min}, 10$ at $5 \mathrm{~min}$ \\
\hline Birth weight & $3.6 \mathrm{~kg}$ & $4.45 \mathrm{~kg}$ \\
\hline Head circumference & $34.6 \mathrm{~cm}$ & $35 \mathrm{~cm}$ \\
\hline Dysmorphism & $\begin{array}{l}\text { Gothic palate, hypertelorism, dysplastic nails, } \\
\text { knee contractures, microgenitalia }\end{array}$ & $\begin{array}{l}\text { Gothic palate, hypertelorism, dysplastic nails, } \\
\text { knee and ankle contractures }\end{array}$ \\
\hline Lipodystrophy & Absent & Absent \\
\hline Epilepsy & Seizures starting at 6 months, mostly myoclonic & Seizures starting at 5 weeks, tonic episodes with apnea \\
\hline Visual fixation & Absent & Absent \\
\hline Muscular tone & Hypotonia & Hypotonia \\
\hline Microcephaly & 3 rd percentile at age $3(45 \mathrm{~cm})$ & 25th-50th percentile at age $1.5(46.6 \mathrm{~cm})$ \\
\hline Brain MRI ${ }^{\mathrm{A}}$ & Normal pons and cerebellum & Normal pons and cerebellum \\
\hline Electroencephalogram & Severely abnormal & Severely abnormal \\
\hline Electroretinogram & Normal & Very low amplitude (early retinopathy) \\
\hline Liver, spleen & Hepatosplenomegaly & Hepatosplenomegaly \\
\hline Transaminases & AST $736 \mathrm{U} / \mathrm{L}(0-54)$ ALT $787 \mathrm{U} / \mathrm{L}(0-67)$ & AST $119 \mathrm{U} / \mathrm{L}(0-54)$ ALT $136 \mathrm{U} / \mathrm{L}(0-67)$ \\
\hline Creatine kinase & $2,078 \mathrm{U} / \mathrm{L}(20-155)$ & $218 \mathrm{U} / \mathrm{L}(20-155)$ \\
\hline Antithrombin & Not done & $\begin{array}{l}\text { Prothrombin test } 13.3 \mathrm{~s}(14-18) \text {, } \\
\text { APTT } 40.7 \mathrm{~s}(23-33) \text {, INR } 0.9\end{array}$ \\
\hline Coagulation factors & Not done & Factor XI:C assay $0.31 \mathrm{IU} / \mathrm{mL}(0.6-12)$ \\
\hline
\end{tabular}

${ }^{\mathrm{A}} \mathrm{MRI}$, magnetic resonance imaging.

sists of 2 subunits encoded by 2 genes, DPM1 $(13,14)$ and DPM2 (15). Cell lines with impaired DolP-Man synthase activity exhibit altered $\mathrm{N}$-linked protein glycosylation; glycosylphosphatidylinositol-anchor (GPIanchor) biosynthesis (16) and C-linked protein mannosylation (17) are also affected. Herein we describe the identification of DolP-Man synthase deficiency caused by mutations in the DPM1 gene as the primary cause for a novel type of CDG, which we call CDG-Ie.

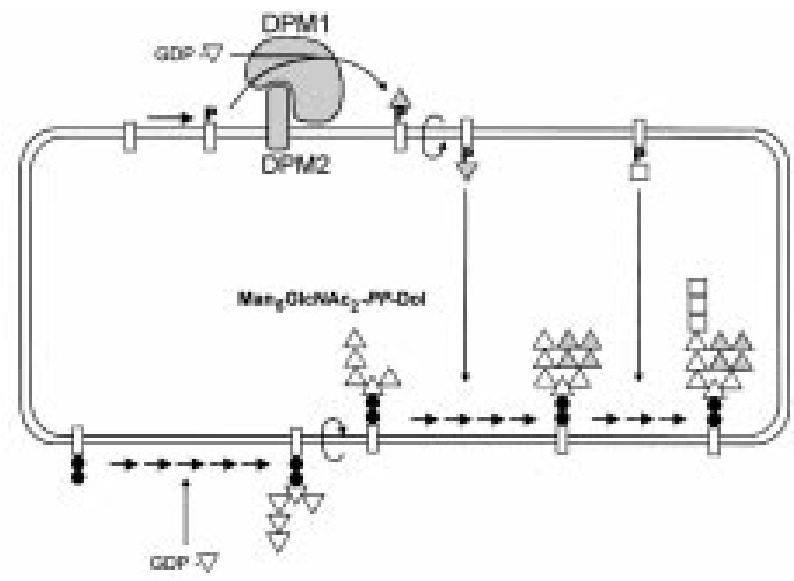

Figure 1

Assembly of the oligomannose core in the ER. Mannose (triangles) is first incorporated into dolichol-bound oligosaccharides (rectangles) from the GDP-Man donor substrate. After flipping into the luminal side, $\mathrm{Man}_{5} \mathrm{GlcNAc}_{2}-P P$-Dol is further decorated with 4 mannoses provided by DolP-Man. The formation of DolP-Man from GDP-Man is catalyzed by the DolP-Man synthase enzyme, which is constituted of a catalytic subunit (Dpm1) and a membrane-anchored subunit (Dpm2). Once fully mannosylated, the core receives 3 glucose residues (squares) before being transferred by the oligosaccharyltransferase complex onto nascent glycoproteins. Filled circles, GlcNAc.

\section{Methods}

Patient cells. Primary fibroblasts isolated from a skin biopsy were grown in DMEM/F12 with high glucose levels (Life Technologies Inc., Paisley, Scotland) supplemented with $10 \%$ FCS. Alternatively, cells were cultured in medium supplemented with $5 \mathrm{mM} \alpha$-D-mannose (Sigma-Aldrich Co., Buchs, Switzerland) for 15 days.

$P M M$ and PMI assays. PMM and PMI activities were measured in enucleated fibroblast cell lysates using the assays of Van Schaftingen and Jaeken (18).

Isoelectric focusing and Western blot. Isoelectric focusing separation of serum transferrin was performed as described previously (19). Proteins from $100-\mu \mathrm{L}$ cerebrospinal fluid samples were precipitated with ethanol and then resuspended in Laemmli buffer (20). Proteins were separated under reducing conditions by SDSPAGE. After transfer to nitrocellulose, $\beta$-trace protein was detected using an anti- $\beta$-trace protein monoclonal antibody (provided by H.S. Conradt, Gesellschaft für Biotechnologische Forschung mblt, Braunschweig, Germany) (21).

Analysis of lipid-linked oligosaccharides. Fibroblast cells grown to $90 \%$ confluence on $530-\mathrm{cm}^{2}$ plates were washed with PBS and then incubated for 90 minutes at $37^{\circ} \mathrm{C}$ in minimal Eagle's medium (Life Technologies Inc.) supplemented with 5\% dialyzed FCS. After this initial incubation period, cells were labeled by the addition of $175 \mu \mathrm{Ci}\left[{ }^{3} \mathrm{H}\right]$ mannose (Amersham Pharmacia Biotech, Freiburg, Germany) for 1 hour at $37^{\circ} \mathrm{C}$. Cells were then washed twice with ice-cold PBS and scraped off in $10 \mathrm{~mL}$ methanol and $0.1 \mathrm{mM}$ Tris, pH 7.4 (8:3 $\mathrm{vol} / \mathrm{vol})$. After the addition of $10.9 \mathrm{~mL}$ chloroform and extensive mixing of the samples, cells were collected by centrifugation at $5,300 \mathrm{~g}$ for 5 minutes. Lipid-linked 


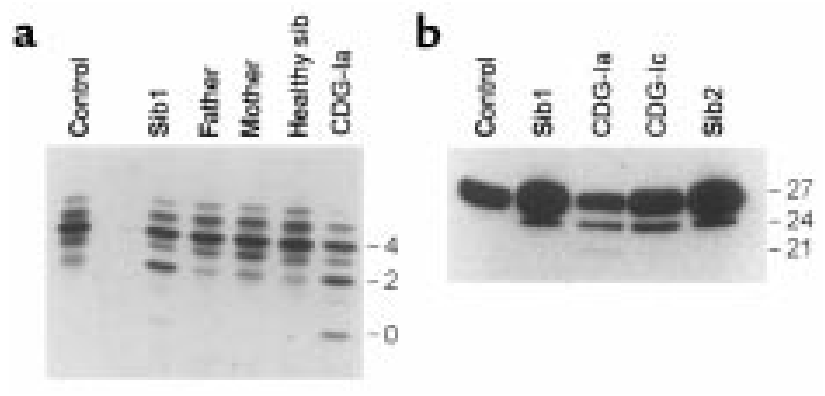

Figure 2

Isoelectric focusing and Western blotting. (a) Serum transferrin was separated by isoelectric focusing. The anode is at the top. The number of negative charges is indicated at the right. (b) $\beta$-trace protein was analyzed by SDS-PAGE followed by Western blotting. Molecular weights (in $\mathrm{kDa}$ ) are given at the right. (Sib1 and sib2 are described in Table 1.)

oligosaccharides were extracted as described previously (8) and were analyzed by HPLC (22).

DolP-Man synthase assay. Fibroblasts grown on a $530-\mathrm{cm}^{2}$ plate were trypsinized and washed twice in ice-cold PBS. Cells were lysed on ice in $50 \mathrm{mM}$ HEPES ( $\mathrm{pH} 7.4), 25 \mathrm{mM}$ $\mathrm{KCl}, 5 \mathrm{mM} \mathrm{MgCl}_{2}, 5 \mathrm{mM} \mathrm{MnCl}_{2}$, and $0.2 \%$ Triton X-100 for 15 minutes; nuclei were removed by centrifugation. DolP-Man synthase activity was assayed using $30 \mu \mathrm{L}$ of cell lysate in $100 \mu \mathrm{L}$ of the same buffer, with the addition of $40 \mu \mathrm{g} / \mathrm{mL}$ DolP (Sigma-Aldrich Co.) and $17 \mu \mathrm{M}$ GDP$\left[{ }^{14} \mathrm{C}\right]$ mannose (Amersham Pharmacia Biotech). Reaction mixtures were incubated for 0,5 , and 15 minutes at $37^{\circ} \mathrm{C}$. DolP-Man was isolated by organic extraction (23), and the radioactivity was measured in a beta counter (Beckman Coulter Inc., Fullerton, California, USA).

RT-PCR. Extraction of total RNA from patient and control fibroblasts $\left(2 \times 10^{7}\right)$ was performed by the procedure of Chomczynski and Sacchi (24). Eight micrograms of total RNA and 100 units of Moloney murine leukemia virus reverse transcriptase (New England Biolabs Inc., Beverly, Massachusetts, USA) were used for reverse transcription. The reaction mixture $(100 \mu \mathrm{L}$ total volume) was incubated for 2 hours at $37^{\circ} \mathrm{C}$. DPM1 cDNA (13) was amplified by PCR using the primer pair 5'-CATGGCCTCCTTGGAAGTCAG-3' and 5'ACCAGGCTTCTTTCATGTTTAACC- $3^{\prime}$, with $8 \mu \mathrm{L}$ reverse transcription product as template. The cycling conditions were 35 cycles at $94^{\circ} \mathrm{C}$ for 45 seconds, $56^{\circ} \mathrm{C}$ for 30 seconds, and $72^{\circ} \mathrm{C}$ for 1 minute, preceded by 6 cycles performed at higher annealing temperatures (twice at $65^{\circ} \mathrm{C}$, twice at $63^{\circ} \mathrm{C}$, twice at $60^{\circ} \mathrm{C}$ ).

Genomic PCR. The human DPM1 cDNA sequence (GenBank accession D86198) was used to screen the available databases using the basic local alignment search tool (BLAST) algorithm (25). One human genomic sequence from a BAC contig on chromosome 20q13 (accession AL334553) was found to include the DPM1 gene. Exon and intron boundaries were determined by alignment of the genomic sequence with the cDNA sequence. The regions including exons 3 and 8 of the human DPM1 gene were amplified with the primers 5'-TGCTTTAAAGTTCTAACAAGTGCAA-3' and 5'-
AgCAGGTGTGAGGGGTTAGA-3', and 5'-ACCAATGGCCAGTGAAAGTT-3' and 5'-AAACCTTACTGCTCCTTTACCA-3', respectively.

$D N A$ sequencing. PCR fragments were purified using GENECLEAN (Bio 101 Inc., Carlsbad, California, USA) or QIAquick (QIAGEN Gmblt, Hilden, Germany) DNA purification kits. Sequencing was performed by a combination of cycle sequencing using the ThermoSequenase fluorescent-labeled primer cycle sequencing kit with 7-deaza dGTP, and solid phase sequencing using the AutoRead Sequencing Kit (both from Amersham Pharmacia Biotech). The sequences were analyzed on an ALF DNA sequencer (Amersham Pharmacia Biotech). Cloning of buman DPM1 CDNA and site-directed mutagenesis. DPM1 cDNA was amplified by PCR as described above using $100 \mathrm{ng}$ of the human T-cell cDNA library as template (26), and 4 units of Klentaq polymerase (Sigma-Aldrich Co.). The resulting 840-bp fragment was subcloned into the SmaI site of pBluescript II SK+ (Stratagene, La Jolla, California, USA). Site-directed mutagenesis was performed using $100 \mathrm{ng}$ of the resulting plasmid (pBS-DPM1wt) as template, and 4 units of Klentaq polymerase. The primers applied to introduce the $274 \mathrm{C}>\mathrm{G}$ mutation were $5^{\prime}$-CATGGCCTCCTTGGAAGTCAG-3', 5'-CCCAACTTTTTCTCTCCTGGTCTTAG-3', 5'-TCTAAGACCAGGAGAGAAAAAGTTG-3', and 5'-ACCAGGCTTCTTTCATGTTTAACC-3'. The primers used to introduce the 628 delC deletion were 5'-CATGGCCTCCTTGGAAGTCAG-3', 5'-TCTGAAGACG-

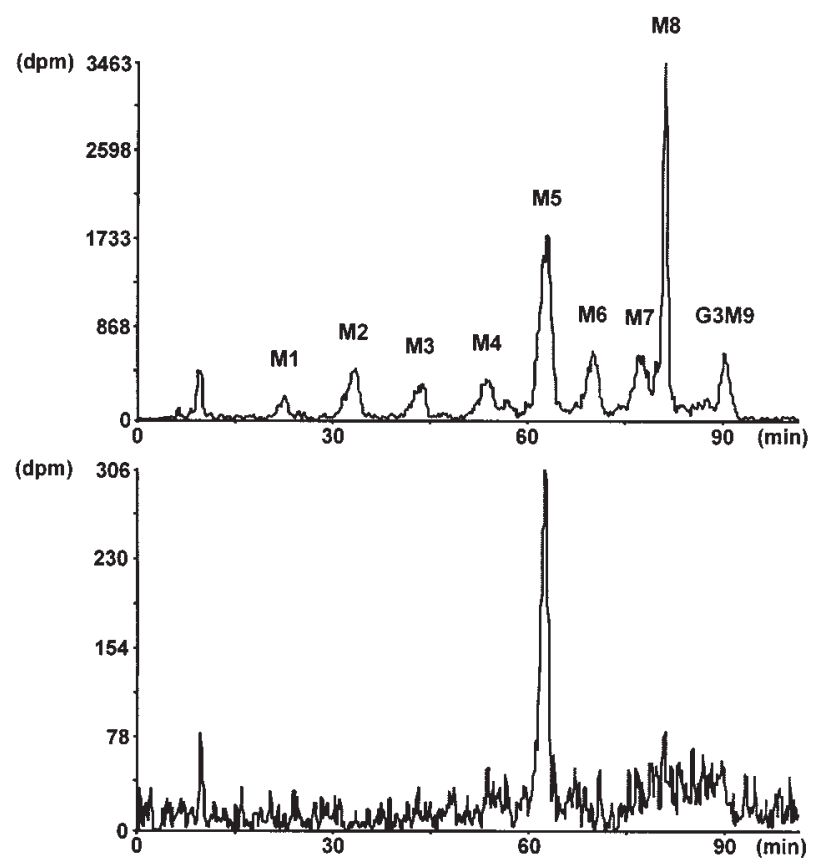

\section{Figure 3}

Lipid-linked oligosaccharide profile in a CDG-le patient. $\left[{ }^{3} \mathrm{H}\right.$ ] oligosaccharides were separated by HPLC after labeling CDG fibroblasts with $\left[{ }^{3} \mathrm{H}\right]$ mannose for 1 hour. The top profile shows the retention times of yeast-derived oligosaccharide standards from $\mathrm{Man}_{1} \mathrm{GlcNAc}_{2}$ (M1) to $\mathrm{Glc}_{3} \mathrm{Man}_{9} \mathrm{GlcNAc}_{2}$ (G3M9). The bottom profile shows the $\mathrm{Man}_{5} \mathrm{GlcNAc}_{2}$ peak accumulating in the fibroblasts from a CDG-le patient. 


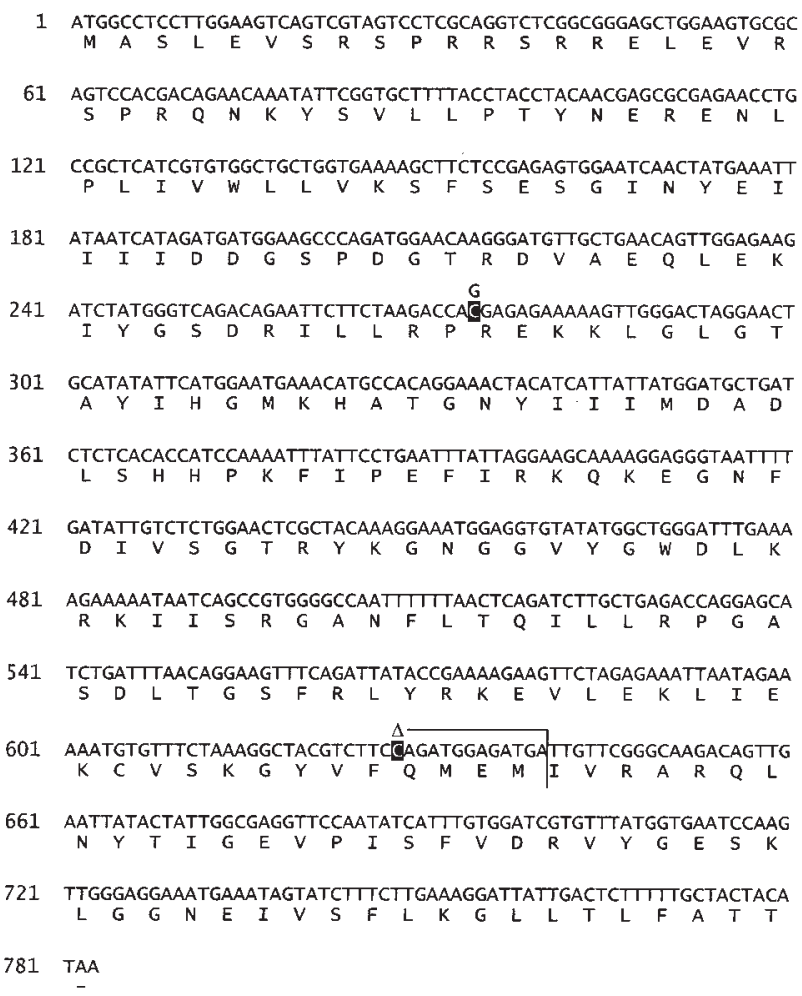

Figure 4

Two mutant alleles of the DPM1 gene in CDG-le patients. The positions of the $274 C>G$ and $628 \mathrm{delC}$ mutations are marked in black on the human DPM1 cDNA sequence. The early termination of DPM1 translation caused by the $628 \mathrm{delC}$-mediated frameshift is shown as a vertical line at position 640 of the cDNA.

TAGCCTTTAGAAACAC-3', 5'-TCTTCAGATGGAGATGATTGTTCG-3', and 5'-ACCAGGCTTCTTTCATGTTTAACC-3'. Twenty PCR cycles were carried out at $94^{\circ} \mathrm{C}$ for 45 seconds, $52^{\circ} \mathrm{C}$ for 30 seconds, and $68^{\circ} \mathrm{C}$ for 60 seconds. The PCR products were gel purified, and the corresponding fragments were mixed and used as template for a second PCR that used the full-length primers to obtain the 2 DPM1 fragments with the designed mutations. The accuracy of the obtained fragments was confirmed by sequencing. The DPM1 cDNA sequence and the 2 mutant variants were directionally subcloned into the BamHI-XhoI sites of the mammalian expression vector pcDNA3.1+ (Invitrogen, Corp. Carlsbad, California, USA).

Transfection of BW5147 cells. The mouse BW5147 Thy1null cells of complementation class E (Thy1-E cells; 27) were generously provided by Robert Hyman (The Salk Institute, San Diego, California, USA), and were cultured in DMEM supplemented with 10\% FCS. For transfection, $20 \mu \mathrm{g}$ of plasmid DNA was mixed with $10^{7}$ cells resuspended in cold PBS. Cells were electroporated with a Gene Pulser (Bio-Rad, Hercules, California, USA) set at $250 \mathrm{~V}$ and $960 \mu \mathrm{F}$. After a 10 -minute resting period on ice, cells were resuspended in cell medium and incubated at $37^{\circ} \mathrm{C}$ for 3 days.

Flow cytometry. FITC-labeled antibodies to mouse Thy1.1 and human CD59 were purchased from
PharMingen (San Diego, California, USA). Before addition of anti-Thy1.1 antibody, BW5147 cells were incubated with anti-CD16/CD32 antibody for 10 minutes on ice to block Fc receptor-mediated antibody binding. Cells were washed twice with PBS and 1\% FCS and then incubated with diluted (1:100) antibodies for $15 \mathrm{~min}$ utes on ice. After rinsing cells once in PBS and 1\% FCS, fluorescence was analyzed on a FACScan flow cytometer equipped with CellQUEST software (Becton Dickinson, Franklin Lakes, New Jersey, USA).

\section{Results}

Two siblings (a boy 3 years and 4 months of age, and his younger sister aged 19 months) were hospitalized after repeated seizure episodes. They were born at term after an uneventful pregnancy. In both children, weight, length, and head circumference was normal at birth, but microcephaly developed in early childhood. Hypertelorism, gothic palate, small hands with dysplastic nails, and knee contractures were observed. Notably, nipples were not inverted as is found in CDG type Ia. Because of a failure to thrive, the younger child received nasogastric feeding. Her early childhood was complicated by recurrent infections. Severe epilepsy started in the girl at the age of 5 weeks, and in her brother at the age of 6 months. Both children were hypotonic and showed a severe global developmental delay. There was no visual fixation, and they were unable to interact socially. Electroencephalogram was severely abnormal with bilateral epileptiform changes. Magnetic resonance imaging of the brain revealed widening of the frontotemporal lobe and the ventricular system but normal pons and cerebellum. A very low flash electroretinogram suggested early retinopathy in the baby girl. Both children showed recurrent moderately elevated transaminases and creatine kinase, and signs of mild coagulopathy (Table 1).

Isoelectric focusing of serum transferrin showed decreased tetrasialotransferrin and increased disialotransferrin and asialotransferrin levels, suggesting a possible lack of entire N-glycan chains (Figure 2a). The hypoglycosylation phenotype was also detected in cerebrospinal fluid, as shown by the presence of hypoglycosylated $\beta$-trace protein (Figure $2 \mathrm{~b}$ ). These patterns were reminiscent of the distribution observed in CDG types Ia, Ib, and Ic.

However, PMM and PMI activity levels were found to be normal in the patients' fibroblasts (data not shown). We investigated the profile of dolichol-bound oligosaccharides in the ER to detect a possible defect in the assembly of the oligomannose core. This analysis revealed an accumulation of the $\mathrm{Man}_{5} \mathrm{GlcNAc}_{2}-\mathrm{PP}$ Dol precursor structure in both patients (Figure 3). This accumulation was indicative of decreased availability of DolP-Man, the substrate for mannosyltransferases that act in the lumen of the ER (see Figure 1). Alternatively, a block at the level of the $\mathrm{Man}_{5} \mathrm{GlCNAc}_{2}$ $P P$-Dol-dependent mannosyltransferase would yield a phenotype similar to that observed in the Saccha- 


\begin{tabular}{|c|c|c|c|c|c|c|}
\hline & & & & & & \\
\hline 1 & 2 & & 45 & 6 & 7 & 89 \\
\hline 1 & t & & It & t & & \\
\hline & & & tf & T & 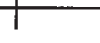 & T. \\
\hline ATG & & & & & & TAA \\
\hline Exon & Size (bp) & & Splice junctions & & Intron & Size (bp) \\
\hline 1 & 173 & atctgg & $\begin{array}{l}-12 \\
\text { CTCA-EX1-PGGAG }\end{array}$ & gtagcg & & \\
\hline 0 & (non & 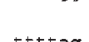 & $162 \quad 261$ & ar & 1 & 3077 \\
\hline & & tettag & & & 2 & 6523 \\
\hline 3 & 34 & ctacag & $\begin{array}{l}262 \\
\text { CTTC-EX3--CTAG }\end{array}$ & gtaagt & & \\
\hline 4 & 77 & tettag & ${ }_{G A A C-E X 4-C C A T}^{296}$ & gtaagt & 3 & 2705 \\
\hline 5 & 26 & tttcag & ${ }^{373}$ CCAA-EX5-ITAG & gtaggt & 4 & 84 \\
\hline 6 & 96 & ctacag & ${ }_{39 A A G-E X 6-T C A G}^{494}$ & gtaggt & 5 & 3610 \\
\hline 7 & 69 & tggcag & ${ }_{\text {C.5GT-EX7-TCAG }}^{593}$ & gtacag & 6 & 1097 \\
\hline 8 & 115 & ttacag & $\begin{array}{l}564 \\
\text { ATTA--EX8--CGAG }\end{array}$ & gtatgo & 7 & 4602 \\
\hline 9 & 369 & aactag & $\begin{array}{l}679 \\
\text { GTTC-EXY--AAGT }\end{array}$ & attgct & 8 & 911 \\
\hline
\end{tabular}

Figure 5

Genomic organization of the human DPM1 gene. Exons are numbered and represented as filled rectangles. Introns are indicated as solid lines. The positions of initiation and termination of translation are symbolized by ATG and TAA, respectively. The sizes of the exons and introns are shown proportionally. The bottom panel shows the sizes and boundaries of the DPM1 exons and introns.

romyces cerevisiae alg3 yeast mutant, which lacks this mannosyltransferase activity $(28,29)$.

The coding sequences of the 3 candidate genes (DPM1, DPM2, and the ALG3 mannosyltransferase gene) were investigated in the patients. Whereas human DPM1 and DPM2 cDNA have been cloned previously, the human gene orthologous to the ALG3 mannosyltransferase gene was not known as such, although its cDNA had been isolated and specified as encoding a Not56-like protein (GenBank accession Y09022). The sequences of the DPM2 and ALG3 mannosyltransferase cDNA of the patients revealed no abnormality (not shown). However, based on cDNA analysis, 2 mutant DPM1 alleles were identified in the patients. The $2 \mathrm{sib}-$ lings and their mother were found to be heterozygous for a $\mathrm{C} \rightarrow \mathrm{G}$ transversion at position 274 , resulting in arginine-to-glycine substitution (R92G). The 2 children were also heterozygous for an allele with a $\mathrm{C}$ deletion at position 628 that was also detected in the father. The mutation resulted in a premature stop of the translation at position 640 (codon 213) (Figure 4).

Comparison of Dpm 1 protein sequences from several species indicated that the arginine residue at position 92 was semiconserved. This was found in Caenorhabditis briggsiae and Schizosaccharomyces pombe, but not in Saccharomyces cerevisiae, Trypanosoma brucei, or Ustilago maydis (14). It is worth noting that the species in which the R92 residue is conserved contain a class of DolP-Man synthase constituted of 2 subunits, Dpm 1 and Dpm2.

The genomic structure of the DPM1 gene was elucidated to confirm the presence of the mutations at the genomic level. The genomic organization of DPM1 had been only partially characterized, with the first 3 exons revealed (13). To complete the task, we first searched
GenBank for possible genomic sequences that would include the DPM1 gene. In fact, a contig sequence (accession AL334553) on chromosome 20q13 was found to contain the entire DPM1 gene, which spans $23.6 \mathrm{kbp}$. The DPM1 gene was split in 9 exons (Figure 5). Examination of the exon-intron boundaries showed that the $274 \mathrm{C}>\mathrm{G}$ mutation was in exon 3 and the 628 delC deletion was in the middle of exon 8 , thereby excluding possible splicing artifacts. Sequencing of exons 3 and 8 in the CDG patients and their parents confirmed the mutations found at the cDNA level (data not shown).

DolP-Man synthase activity was measured in fibroblasts from the CDG patients and from healthy control subjects. An activity of $11.8 \mathrm{pmol} / \mathrm{min}$ per $\mathrm{mg}$ protein was found in control cells, and a residual activity of 0.7 $\mathrm{pmol} / \mathrm{min}$ per $\mathrm{mg}$ protein was detected in the CDG cells. Although DolP-Man synthase activity in the CDG fibroblasts was decreased to $6 \%$ of the normal level, the remaining activity was significantly above the detection limit of the assay, indicating that the 2 mutations identified in the DPM1 gene of CDG patients did not completely inactivate the enzyme. To determine the impact of each mutation on DolP-Man synthase activity, we engineered DPM1 expression vectors that expressed either the wild-type cDNA, the $274 \mathrm{C}>\mathrm{G}$ mutation, or the 628 delC deletion. The constructs were transfected into mouse BW5147 Thy1-E cells (27), which are deficient in DolP-Man synthase activity due to inactive Dpm1 enzyme (13). Restoration of Thy1 expression was analyzed by flow cytometry 3 days after transfection. Cells transfected with a construct expressing wildtype DPM1 reacted positively for Thy1 staining, whereas cells transfected with an empty vector remained
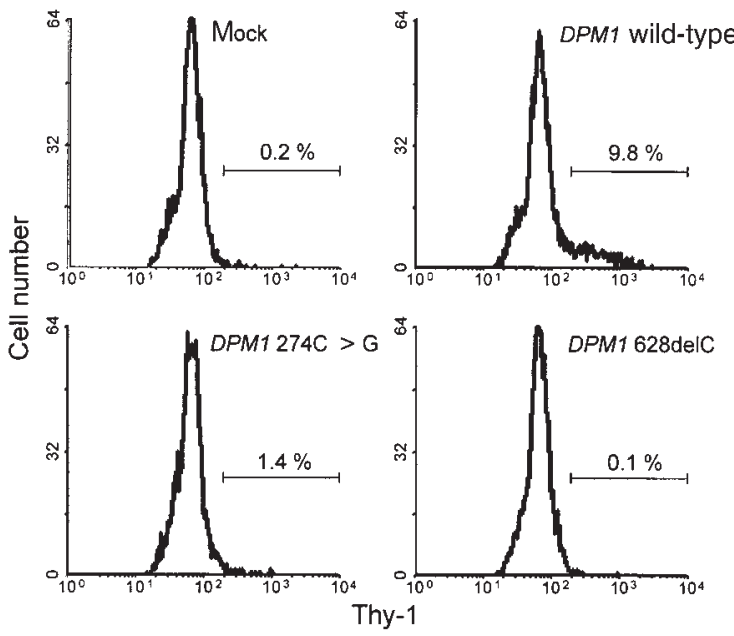

\section{Figure 6}

Complementation of Thy1-E cells. BW5147 Thy1-null cells, transfected with DPM1 expression vectors, were analyzed for Thy1 staining by flow cytometry. Each panel shows the fluorescence histogram obtained for cells transfected with a mock vector, the human DPM1 wild-type cDNA, the human DPM1 274C>G cDNA, and the DPM1 628delC cDNA. The region marked with the horizontal bar denotes the percentage of Thy1-positive cells. 


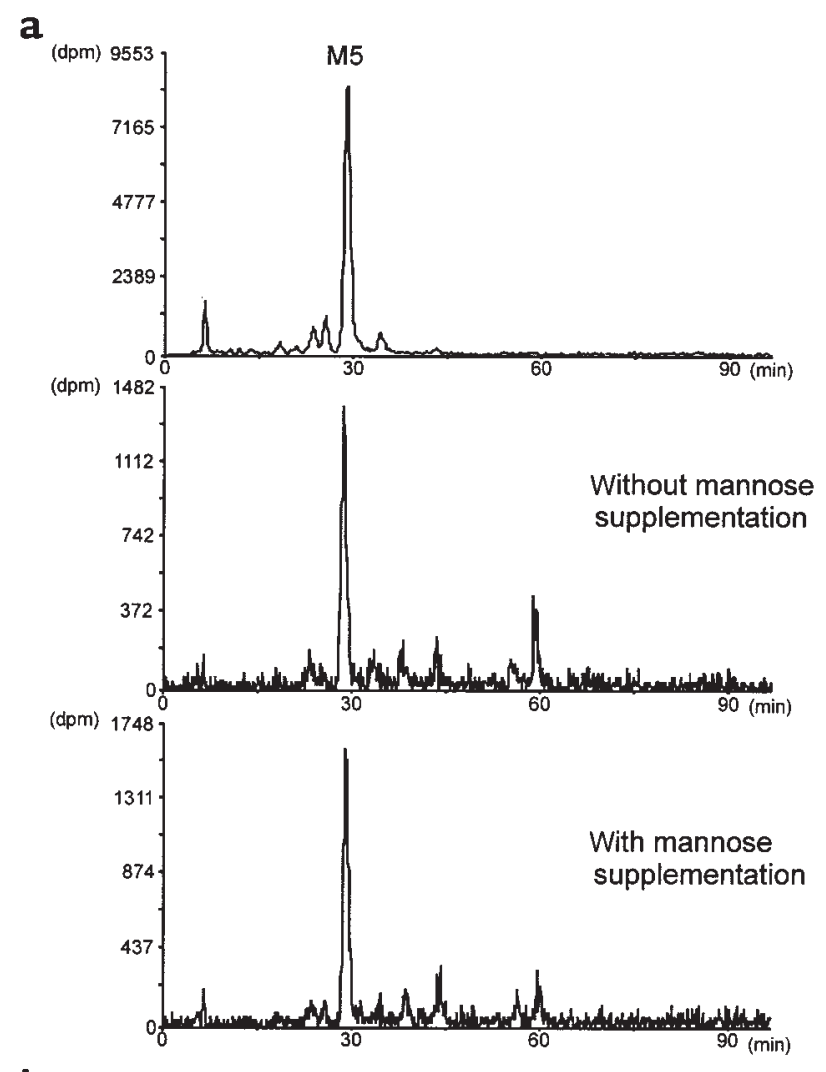

b

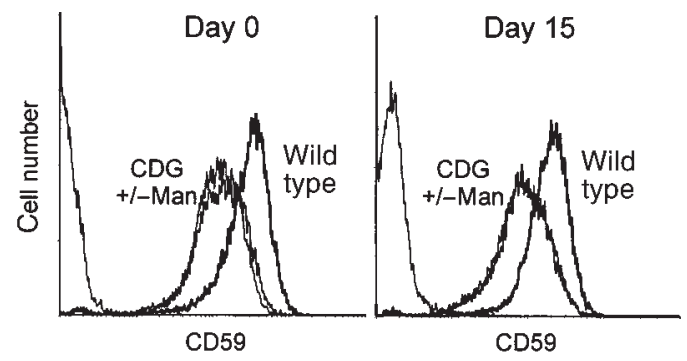

Figure 7

Mannose supplementation in CDG fibroblasts. Lipid-linked oligosaccharide profiles (a) and CD59 levels (b) were analyzed in CDG cells cultured for 15 days in the presence of $5 \mathrm{mM}$ mannose. The top panel shows the HPLC elution profile of the $\mathrm{Man}_{5} \mathrm{GlcNAc}_{2}$ standard (M5) derived from the Saccharomyces cerevisiae alg3 yeast mutant cells.

Thy1-negative (Figure 6). A small population of Thy1positive cells was detected after transfection with the $D P M 1$ gene containing the $274 \mathrm{C}>\mathrm{G}$ substitution, indicating that this mutation does not abolish DolP-Man activity. By contrast, the transfection of Thy1-E cells with the vector including the DPM1 gene with the 628 delC deletion failed to restore Thy 1 expression at all (Figure 6); this is compatible with the observation that a deletion of the $24 \mathrm{COOH}$-terminal amino acids also abolished DolP-Man synthase activity (15).

Depletion of GDP-Man caused by deficiencies in PMM and PMI, and the resulting protein hypoglycosylation can be improved in vitro by supplementing with 1-2 mM mannose in the cell culture medium $(30,31)$. To evaluate whether the DolP-Man synthase deficien- cy detected in CDG patients can be overcome by mannose addition, we cultured the CDG fibroblasts in the presence or absence of $5 \mathrm{mM} \alpha$-D-mannose for a period of 15 days. The dolichol-bound oligosaccharides were then analyzed in both cell populations. At the same time, we analyzed the levels of the GPI-anchored protein CD59 at the surface of CDG fibroblasts before and after mannose supplementation. Identical lipid-linked oligosaccharide profiles were detected in cells cultured with or without the addition of mannose (Figure 7a). Similarly, after mannose supplementation, the CD59 levels measured on DPM1-deficient CDG fibroblasts remained unchanged, at $40 \%$ of the amount normally found on fibroblast cells (Figure $7 \mathrm{~b}$ ).

\section{Discussion}

We have identified a novel type of CDG caused by a deficiency in DolP-Man synthase activity. The shortage of DolP-Man affects the biosynthesis of the lipid-linked $\mathrm{Glc}_{3} \mathrm{Man}_{9} \mathrm{GlcNAc}_{2}$ substrate for $\mathrm{N}$-linked protein glycosylation, and results in a suboptimal $\mathrm{N}$-glycosylation of nascent glycoproteins and suboptimal biosynthesis of GPI-anchored proteins. Because DolP-Man deficiency causes hypoglycosylation of proteins similar to that encountered in CDG-I, we propose to classify this novel ER-associated defect as CDG-Ie. Clinically, apart from the psychomotor retardation and the marked hypotonia, these patients are quite different from CDG-Ia patients. By contrast, CDG-Ie patients show striking similarities with the patients reported by Stibler et al. and defined as CDG type IV (32). The molecular basis of the defect underlying the glycosylation deficiency in these type IV patients has not been disclosed yet, but we speculate that it may be either identical to the defect presented here or otherwise related to an alteration at the level of DolPMan availability or incorporation into oligosaccharides.

DolP-Man serves as donor substrate in the process of $\mathrm{N}$-linked protein glycosylation, GPI-core biosynthesis, and C-glycosylation of proteins (17). Therefore, a limitation in the DolP-Man pool can possibly affect the formation of different types of glycoproteins. Indeed, we detected decreased levels of the GPI-anchored CD59 protein at the surface of CDG-Ie fibroblasts. Similarly, the shortage of mannose-1-phosphate caused by both PMM and PMI deficiencies may also affect the same pathways, because GDP-Man is the substrate for DolP-Man synthesis. However, analysis of CD59 levels on fibroblasts of several CDG-Ia and -Ib patients revealed normal levels (data not shown). Because GDP-Man not only serves as a substrate for DolP-Man synthesis, the differences in the biochemical and clinical representation of CDG-Ia and CDG-Ib vs. CDG-Ie can be understood on this basis. In addition, it is important to note that all mutations that cause the clinical picture of CDG are missense mutations allowing for some residual activity of the affected protein. The extent of this residual activity strongly affects the clinical picture of the CDG patients.

In this respect it is interesting to note that in this first described case of CDG-Ie, the combination of a severe 
deletion with a missense mutation is observed: the deletion $628 \mathrm{delC}$ causes a complete inactivation of the protein (Figure 6) (15), whereas $274 \mathrm{C}>\mathrm{G}$ seems to be a mild mutation. It may well be that, analogous to the PMM2 mutations in CDG-Ia (33), homozygosity for the severe $628 \mathrm{delC}$ mutation is lethal. This fits with the observation of a relatively mild mutation in combination with a deletion, yielding an inactive enzyme. It is possible that homozygosity for the $274 \mathrm{C}>\mathrm{G}$ mutation may leave enough DolP-Man synthase activity to prevent a shortage of DolP-Man with pathological consequences.

The form of CDG caused by PMI deficiency (CDG-Ib) can be successfully treated with oral mannose (5). Because DolP-Man synthase activity was not completely lost in the CDG-Ie fibroblasts, we thought that an elevation of the cellular mannose pool might force the defective enzyme to produce more DolP-Man. However, our data showed that the addition of mannose had no effect on the hypoglycosylation phenotype of CDG-Ie cells. It is probable that an excess of intracellular mannose does not lead to the high pool of GDP-Man required for increasing the synthesis of DolP-Man. It is possible that a conversion of GDP-Man to GDP-fucose (34) lowers the GDP-Man pool in mannose-fed cells. In any case, considering the severe symptomatology, it is unlikely that supplementation therapy would improve the condition of CDG-Ie patients.

\section{Acknowledgments}

We thank Emile van Schaftingen for measuring the PMM and PMI activity in fibroblast cells, Bob Hyman and Andreas Conzelmann for kindly providing us with BW5147 cells, and Bea Berger for assisting with cell cultivation. This work was supported by the Swiss National Science Foundation (grant 3100-46836.96 to E.G. Berger and T. Hennet, and grants 3100-040350.94 and 3157082.99 to M. Aebi) and by grant G.0243.98 from the Fund for Scientific Research-Flanders to G. Matthijs.

1. Jaeken, J., Carchon, H., and Stibler, H. 1993. The carbohydrate-deficient glycoprotein syndromes: pre-Golgi and Golgi disorders? Glycobiology. 3:423-428.

2. Krasnewich, D., and Gahl, W.A. 1997. Carbohydrate-deficient glycoprotein syndrome. Adv. Pediatr. 44:109-140.

3. Varki, A. 1993. Biological roles of oligosaccharides: all of the theories are correct. Glycobiology. 3:97-130.

4. Matthijs, G., et al. 1997. Mutations in PMM2, a phosphomannomutase gene on chromosome $16 \mathrm{p} 13$, in carbohydrate-deficient glycoprotein type I syndrome (Jaeken syndrome). Nat. Genet. 16:88-92.

5. Niehues, R., et al. 1998. Carbohydrate-deficient glycoprotein syndrome type Ib. Phosphomannose isomerase deficiency and mannose therapy. J. Clin. Invest. 101:1414-1420.

6. Jaeken, J., et al. 1998. Phosphomannose isomerase deficiency: a carbohydrate-deficient glycoprotein syndrome with hepatic-intestinal presentation. Am. J. Hum. Genet. 62:1535-1539.

7. Imbach, T., et al. 1999. A mutation in the human ortholog of the Saccharomyces cerevisiae ALG6 gene causes carbohydrate-deficient glycoprotein syndrome type-Ic. Proc. Natl. Acad. Sci. USA. 96:6982-6987.

8. Burda, P., et al. 1998. A novel carbohydrate-deficient glycoprotein syndrome characterized by a deficiency in glucosylation of the dolichol- linked oligosaccharide. J. Clin. Invest. 102:647-652.

9. Körner, C., et al. 1998. Carbohydrate-deficient glycoprotein syndrome type V: deficiency of dolichyl-P-Glc:Man ${ }_{9} \mathrm{GlcNAc}_{2}-P P$-dolichyl glucosyltransferase. Proc. Natl. Acad. Sci. USA. 95:13200-13205.

10. Körner, C., et al. 1999. Carbohydrate deficient glycoprotein syndrome type IV: deficiency of dolichyl-P-Man: Man(5)GlcNAc(2)-PP-dolichyl mannosyltransferase. EMBOJ. 18:6818-6822.

11. Tan, J., Dunn, J., Jaeken, J., and Schachter, H. 1996. Mutations in the MGAT2 gene controlling complex N-glycan synthesis cause carbohydrate-deficient glycoprotein syndrome type II, an autosomal recessive disease with defective brain development. Am. J. Hum. Genet. 59:810-817.

12. Burda, P., and Aebi, M. 1999. The dolichol pathway of N-linked glycosylation. Biochim. Biophys. Acta. 1426:239-257.

13. Tomita, S., et al. 1998. A homologue of Saccharomyces cerevisiae Dpm1p is not sufficient for synthesis of dolichol-phosphate-mannose in mammalian cells. J. Biol. Chem. 273:9249-9254.

14. Colussi, P.A., Taron, C.H., Mack, J.C., and Orlean, P. 1997. Human and Saccharomyces cerevisiae dolichol phosphate mannose synthases represent two classes of the enzyme, but both function in Schizosaccharomyces pombe. Proc. Natl. Acad. Sci. USA. 94:7873-7878.

15. Maeda, Y., Tomita, S., Watanabe, R., Ohishi, K., and Kinoshita, T. 1998. DPM2 regulates biosynthesis of dolichol phosphate-mannose in mammalian cells: correct subcellular localization and stabilization of DPM1, and binding of dolichol phosphate. EMBO J. 17:4920-4929.

16. Sugiyama, E., et al. 1991. Identification of defects in glycosylphosphatidylinositol anchor biosynthesis in the Thy- 1 expression mutants. J. Biol. Chem. 266:12119-12122.

17. Doucey, M.A., Hess, D., Cacan, R., and Hofsteenge, J. 1998. Protein Cmannosylation is enzyme-catalysed and uses dolichyl-phosphate-mannose as a precursor. Mol. Biol. Cell. 9:291-300.

18. Van Schaftingen, E., and Jaeken, J. 1995. Phosphomannomutase deficiency is a cause of carbohydrate-deficient glycoprotein syndrome type I. FEBS Lett. 377:318-320.

19. de Jong, G., and van Eijk, H.G. 1988. Microheterogeneity of human serum transferrin: a biological phenomenon studied by isoelectric focusing in immobilized $\mathrm{pH}$ gradients. Electrophoresis. 9:589-598.

20. Laemmli, U.K. 1970. Cleavage of structural proteins during the assembly of the head of bacteriophage T4. Nature. 227:680-685.

21. Grünewald, S., et al. 1999. $\beta$-Trace protein in human cerebrospinal fluid: a diagnostic marker for $\mathrm{N}$-glycosylation defects in brain. Biochim. Biophys. Acta. 1455:54-60.

22. Zufferey, R., et al. 1995. STT3, a highly conserved protein required for yeast oligosaccharyl transferase activity in vivo. EMBO J. 14:4949-4960.

23. McLachlan, K.R., and Krag, S.S. 1994. Three enzymes involved in oligosaccharide-lipid assembly in Chinese hamster ovary cells differ in lipid substrate preference. J. Lipid Res. 35:1861-1868.

24. Chomczynski, P., and Sacchi, N. 1987. Single-step method of RNA isolation by acid guanidinium thiocyanate-phenol-chloroform extraction. Anal. Biochem. 162:156-159.

25. Altschul, S.F., Boguski, M.S., Gish, W., and Wootton, J.C. 1994. Issues in searching molecular sequence databases. Nat. Genet. 6:119-129.

26. Hennet, T., et al. 1998. Genomic cloning and expression of three murine UDP-galactose: $\beta$ - $N$-acetylglucosamine $\beta 1,3$-galactosyltransferase genes. J. Biol. Chem. 273:58-65.

27. Trowbridge, I.S., and Hyman, R. 1979. Abnormal lipid-linked oligosaccharides in class E Thy-1-negative mutant lymphomas. Cell. 17:503-508.

28. Aebi, M., Gassenhuber, J., Domdey, H., and te Heesen, S. 1996. Cloning and characterization of the ALG3 gene of Saccharomyces cerevisiae. Glycobiology. 6:439-444.

29. Huffaker, T.C., and Robbins, P.W. 1983. Yeast mutants deficient in protein glycosylation. Proc. Natl. Acad. Sci. USA. 80:7466-7470.

30. Panneerselvam, K., and Freeze, H.H. 1996. Mannose corrects altered Nglycosylation in carbohydrate-deficient glycoprotein syndrome fibroblasts. J. Clin. Invest. 97:1478-1487.

31. Körner, C., Lehle, L., and von Figura, K. 1998. Carbohydrate-deficient glycoprotein syndrome type 1: correction of the glycosylation defect by deprivation of glucose or supplementation of mannose. Glycoconj. J. 15:499-505.

32. Stibler, H., Stephani, U., and Kutsch, U. 1995. Carbohydrate-deficient glycoprotein syndrome: a fourth subtype. Neuropediatrics. 26:235-237.

33. Pirard, M., et al. 1999. Effect of mutations found in carbohydrate-deficient glycoprotein syndrome type IA on the activity of phosphomannomutase 2. FEBS Lett. 452:319-322.

34. Sturla, L., et al. 1997. Expression, purification and characterization of GDP-D-mannose 4,6-dehydratase from Escherichia coli. FEBS Lett. 412:126-130. 